\title{
Periscope
}

months and finally healed after extrusion of a sequestrum. Thereafter ten years of health, but the incident is not without its significance. There succeeded pains more or less vague to begin with about the head of the index metatarsal, and naturally the thought of a tuberculous osteomyelitis suggested itself. Radiography showed all the metatarsal bones fully ossified at the age of 14 years, no cartillage of conjugation remained. The head of the affected bone had lost its roundness, was flat, and limited by a narrow strip of normal bone, presented a clean area some 2 to $3 \mathrm{~mm}$. in diameter containing in its centre a little opaque point. The appearances were typical of osteochondritis juvenilis. Rest and local treatment alone were adopted, and after ten months of passivity, improvement was hardly noticeable and recalcification had not progressed.

According to Tavernier this condition, though presenting some literature from Germany and America, is little known in France. Though distinguished by eponymous nomenclature, it is a typical osteochondritis. At the same time there is an injury or a neighbouring inflammatory action and a subsequent localised decalcification which bears no relation to an infective epiphysitis. Tavernier points out that the whole syndrome is so innocuous that treatment by absolute rest over a prolonged period would be unendurable. The periscopist does not share Tavernier's opinion that any such enforced prolonged immobilisation would ensure recalcification.

TAVernier, "Ostéochondrite de la tête du deuxième métatarsien"

$$
\text { (Lyon Chirurg., 1928, xxv., 699.) - D. M. G. }
$$

\section{OBSERVATIONS UPON THE VASCULARITY OF THE HUMAN OCCIPITAL LOBE DURING VISUAL ACTIVITY.}

A case is described here of a man aged twenty-six years in whom there was a circumscribed angioma arteriale racemosum of the left occipital visual cortex which had caused an incomplete right homonymous hemianopsia. Associated with the tumour was a well-marked auscultatory bruit. When the patient was at rest with his eyes closed the bruit was distant and weak. When the patient used his eyes for reading, or attempted to perceive objects to his blind side without otherwise exerting himself, a very marked increase occurred in the bruit, detectable both by auscultation and by electrophonograms. Other types of mental effort, such as straining to hear the tick of a distant watch or various forms of olfactory stimulation, had no influence upon the bruit. It would appear that visual effort was associated in this case with increased vascularisation of the occipital cortex.

J. F. Fulton, Boston (Brain, 1928, li., pp. 310-320). 